NASCENTE, A.S.; PEREIRA, W.; MEDEIROS, M.A. Interferência das plantas daninhas na cultura do tomate para processamento. Horticultura Brasileira, Brasília, v.22, n.3, p.602-606, jul-set 2004.

\title{
Interferência das plantas daninhas na cultura do tomate para processamento $^{1}$
}

\author{
Adriano Stephan Nascente ${ }^{2}$; Welington Pereira ${ }^{3}$; Maria Alice Medeiros ${ }^{3}$ \\ ${ }^{2}$ Embrapa Rondônia, C. Postal: 406, 78900-970 Porto Velho-RO; E-mail: nascente@cpafro.embrapa.br; ${ }^{3}$ Embrapa Hortaliças, C. Postal \\ 218, 70359-970 Brasília-DF; E-mail: wellpe@cnph.embrapa.br; malice@cnph.embrapa.br.
}

\section{RESUMO}

Para se alcançar eficiência no manejo cultural, é muito importante determinar o período crítico de interferência (PCI) das plantas daninhas no cultivo das hortaliças. Avaliou-se neste trabalho a interferência das plantas daninhas na cultura do tomate para processamento, pelo transplantio de mudas, na Embrapa Hortaliças, em delineamento de blocos ao acaso com 3 repetições. Os tratamentos foram divididos em dois grupos, com períodos iniciais crescentes, denominados sem a interferência (no limpo) e com interferência (no mato) das plantas daninhas. No primeiro, a cultura de tomate permaneceu livre da interferência das plantas daninhas desde o transplantio das mudas até os seguintes períodos (dias) do ciclo de desenvolvimento do tomate: 1-28, 1-35, 1-49, 1-63, 177, 1-91 (todo ciclo, colheita). Após estes períodos, as plantas daninhas cresceram livremente até o final do ciclo da cultura. No segundo grupo a cultura permaneceu com a interferência das plantas daninhas desde o preparo final do solo e transplantio das mudas até os mesmos períodos descritos para o primeiro grupo. Após estes períodos as plantas daninhas foram removidas manualmente até a colheita. De um total de 24 , as espécies mais freqüentes e/ou de maior acúmulo de matéria seca foram: Bidens pilosa, Brachiaria plantaginea, Nicandra physaloides e Oxalis latifolia. As plantas daninhas causaram reduções na produção de tomate de até 75,5\%, sendo que o PCI ocorreu no período do $33^{\circ}$ ao $76^{\circ}$ dia após a implantação da cultura.

Palavras-chave: Lycopersicon esculentum, competição, transplantio, período crítico de interferência.

\begin{abstract}
Weed interference in processing tomato crops

Weed control efficiency depends on the information about its interference on the crops. The interference of weed on tomato plants of a processing variety, transplanted directly into the field was evaluated. The field experiment was carried out, in a randomized block design with three replications, at Embrapa Hortaliças in Brasília, Brazil. Plots were laid out with increasing periods of time in the presence or absence of weeds. In the first case, plots remained under weed interference from seedling stage until the following periods (days) of the tomato life cycle: 1-28, 1-35, 1-49, 1-63, 1-77 and 1-91(whole cycle, harvest). After these periods the weeds grew freely until harvesting time. In the second case, plots were weeded from seedling stage until the previously described periods. After these periods weeds were removed by hand through the rest of the tomato cycle. Among 24 of the most frequent weed species, Bidens pilosa, Brachiaria plantaginea, Nicandra physaloides and Oxalis latifolia presented higher dry matter accumulation. Tomato production was reduced by $75.5 \%$ and the critical period of interference occurred from the $33^{\text {th }}$ to the $76^{\text {th }}$ day after transplanting.
\end{abstract}

Keywords: Lycopersicon esculentum, weed competition, transplantation, critical period of interference.

\section{(Recebido para publicação em 25 de junho de 2003 e aceito em 3 de junho de 2004)}

$\mathrm{O}$ tomateiro

(Lycopersicon esculentum Mill.) é uma das hortaliças mais importantes do Brasil e do mundo (Silva et al., 1994, Silva e Giordano, 2000, Cançado Júnior et al., 2003). Devido à sua arquitetura e espaçamento, o tomateiro favorece a ocorrência de plantas daninhas durante o seu ciclo. Para se obter maior sucesso no controle das plantas daninhas é importante que se conheça o período crítico de interferência (PCI) das mesmas com a cultura (Blanco, 1972). Este período, segundo Pereira (1987), está compreendido entre o tempo máximo a partir do transplantio ou da emergência em que a cultura pode conviver com a população de plantas daninhas sem reduzir a produção (período de convivência) e o tempo mínimo a partir do transplantio ou emergência, em que a cultura deve ser mantida livre de plantas daninhas para garantir uma produção satisfatória (período de controle).

O conhecimento do PCI das plantas daninhas permite estabelecer critérios adequados de manejo, tais como: quando eliminá-las para evitar prejuízos na produção; o período mínimo no qual o herbicida precisaria ter ação residual no solo para controlá-las e a época limite para aplicar um herbicida em pós- emergência, além de informações que subsidiem a aplicação de outros métodos de controle de plantas daninhas (Blanco, 1972, Pereira, 1987; Pereira, 2000; Silva et al., 2003).

Até o final do século passado, não existiam no Brasil trabalhos publicados sobre a interferência biológica das plantas daninhas na cultura do tomate para processamento (Pereira, 2000; Silva et al., 2003). Entretanto, estudos realizados em outros países para esta cultura indicaram que o PCI para o tomateiro situou-se entre 20 a 63 dias (Qasem, 1992; Campeglia, 1991; Weaver e Tan, 1987; Weaver, 1984; Weaver e Tan,

\footnotetext{
${ }^{1}$ Parte da Dissertação do primeiro autor no curso de mestrado em Agronomia, UnB.
} 
1983; Friesen, 1979; Sajjapongse et al., 1983). Recentemente, Hernandez et al. (2002) verificaram que à medida que se aumentou a densidade de Solanum americanum Mill. maiores foram as perdas de produtividade do tomateiro. $\mathrm{O}$ índice de competitividade indicou que uma planta desta espécie correspondeu a quase cinco plantas de tomate, mostrando assim a maior agressividade da planta daninha em relação à cultivada.

Segundo Hernandez (2004), o período crítico de interferência de maria-pretinha sobre o tomateiro ocorreu do $27^{\circ}$ ao $46^{\circ}$ dia do cliclo da cultura.

O objetivo deste trabalho foi determinar o período crítico de interferência das plantas daninhas na cultura do tomate para processamento estabelecida a partir de mudas transplantadas.

\section{MATERIAL E MÉTODOS}

O experimento foi conduzido em campo, na Embrapa Hortaliças, em Latossolo Vermelho Escuro, sob vegetação de Cerrado. O preparo do solo, adubação, transplantio das mudas e tratos culturais foram realizados segundo as recomendações de Silva et al. (1994).

A cultivar IPA-5 foi semeada em bandejas de isopor com 200 células piramidais, com $5 \mathrm{~cm}$ de altura, sendo o transplante em junho de 1997, no espaçamento de $1,0 \mathrm{~m}$ entre linhas e 0,4 $\mathrm{m}$ entre plantas. $\mathrm{O}$ delineamento experimental foi blocos casualizados, em 3 repetições, sendo cada unidade experimental constituída por 3 fileiras, com $5,0 \mathrm{~m}$ de comprimento. A primeira fileira de cada parcela e os $0,50 \mathrm{~m}$ das extremidades das fileiras foram utilizadas como bordadura.

Os tratamentos experimentais foram divididos em dois grupos, com períodos iniciais crescentes, denominados sem a interferência (no limpo) e com interferência (no mato) das plantas daninhas. No primeiro, a cultura de tomate permaneceu livre da interferência das plantas daninhas desde o transplantio das mudas de tomate até os seguintes períodos (dias) do seu ciclo de desenvolvimento: 1-28, 1-35, 1-49, 1-63, 177, 1-91 (todo ciclo ou colheita, Tabela 2). Após estes períodos, as plantas daninhas cresceram livremente até o final do ciclo da cultura. No segundo grupo, a cultura permaneceu sob a interferência das plantas daninhas desde o preparo final do solo e transplantio das mudas de tomate até os mesmos períodos descritos para o primeiro grupo de tratamentos. Após estes períodos as plantas daninhas foram removidas manualmente até a colheita. As amostragens das espécies de plantas daninhas foram realizadas ao final de cada período com interferência das mesmas e por ocasião da colheita para os correspondentes períodos que ficaram inicialmente livres da interferência das plantas daninhas. Utilizou-se um quadrado vazado de ferro com dimensão de $0,8 \mathrm{~m}^{2}$, jogado aleatoriamente na parcela útil. Todas as plantas daninhas que estavam na área amostrada foram coletadas, identificadas por família, gênero, espécie e nome vulgar, contando-se também o número de cada espécie, utilizando metodologia semelhante à utilizada por Kuva et al. (2000). As plantas daninhas de cada espécie foram colocadas em sacos de papel e secas em estufa com ventilação forçada a $65^{\circ} \mathrm{C}$ até obter peso constante da matéria seca. Os dados obtidos foram extrapolados para gramas de matéria seca por $\mathrm{m}^{2}$.

Realizou-se duas colheitas manuais da produção de tomate aos 91 dias após o transplante das mudas. As produções totais e comerciais do tomate foram determinadas por meio do número e peso de frutos, sendo considerados frutos comerciais os frutos grandes (peso igual ou superior a $100 \mathrm{~g}$ ) e com ausência de danos. Considerou-se como frutos refugos aqueles danificados por insetos e/ou patógenos, podres, imaturos e pequenos. Os dados obtidos foram extrapolados para t/ha.

Para estimar o período de convivência considerou-se o tempo máximo em dias, no qual as plantas daninhas conviveram com a cultura, causando uma redução de $5 \%$ na produtividade potencial (produção obtida no tratamento todo ciclo sem plantas daninhas). O período de controle foi estimado considerandose o tempo mínimo em dias, no qual as plantas daninhas foram controladas, a fim de garantir $95 \%$ da produtividade potencial. Kuva et al. (2001) estabeleceu-se um nível de $5 \%$ de tolerância de perdas de produção em relação à teste- munha no limpo do plantio à colheita ( $100 \%$ da produção).

Analisando-se a relação entre a produção do tomate, expressa em peso de frutos comerciais, e os períodos iniciais do desenvolvimento da cultura em presença e ausência das plantas daninhas, calculou-se equações de regressão, utilizando-se o programa Table Curve (Jandel Scientific), onde considerou-se a equação que melhor explicava a variação dos dados observados.

Em função das curvas de produção estimadas por estas equações de regressão, estimou-se o período (dias) crítico de interferência das plantas daninhas para a cultura do tomate para processamento. Além disso, calculou-se a equação de regressão que melhor explicava os dados de acúmulo de matéria seca na presença e na ausência de convivência com plantas daninhas.

\section{RESULTADOS E DISCUSSÃO}

As espécies de plantas daninhas que ocorreram na área experimental foram Ageratum conyzoides L., Alternanthera tenella Colla, Amaranthus hybridus L., Bidens pilosa L., Brachiaria decumbens Stapf, Brachiaria plantaginea (Link.) Hitch, Cenchrus echinatus L., Commelina bengalensis L., Cynodon dactylon (L.) Pers., Digitaria sanguinalis (L.) Scop., Eleusine indica (L.) Gaertns., Emilia sonchifolia (L.) DC:, Galinsoga parviflora Cav., Hyptis suaveolens (L.) Poit., Lepidium virginicum L., Malvastrum coromandelianum (L.) Garcke, Nicandra physaloides (L.) Pers., Oxalis latifolia Kunth, Panicum maximum Jacq., Portulaca oleracea (L.) Cronq., Richardia brasiliensis Gomes, Solanum americanum Mill., Sonchus oleraceus L., Sorghum arundinaceum (Willd.) Stapf. e Taraxacum officinale Weber. As espécies mais frequientes e/ou de maior acúmulo de matéria seca na área do experimento foram Bidens pilosa, Brachiaria plantaginea, Nicandra physaloides. e Oxalis latifolia (Tabela 1), todas estas são encontradas freqüentemente em culturas de tomate e contribuem para a redução da produtividade da cultura (Pereira, 1987; Silva et al., 1994 e Pereira, 2000). Pela 
Tabela 1. Frequência das principais plantas daninhas, expressa em \% do número de indivíduos (\%NI) e \% do peso da matéria seca (\%MS), encontradas na área experimental. Brasília, Embrapa Hortaliças, 1997.

\begin{tabular}{|c|c|c|c|c|}
\hline Espécie de planta daninha & Familia & Nome comum & $\% \mathrm{NI}^{\prime}$ & $\% \mathrm{MS}^{2}$ \\
\hline Bidens pilosa & Asteraceae (Compositaceae) & Picāo-preto & 18,22 & 37,84 \\
\hline Brachiaria plantaginea & Poaceae (Gramineae) & Capim-marmelada & 43,93 & 33,72 \\
\hline Nicandra physaloides & Solanaceae & Joá-de-capote & 0,41 & 14,03 \\
\hline Oxalis latifolia & Oxalidaceae & Trevo & 13,88 & 2,23 \\
\hline Outras & - & - & 23,56 & 12,18 \\
\hline Total & - & - & 100 & 100 \\
\hline
\end{tabular}

${ }^{1}$ Os dados desta coluna representam a \% da ocorrência da espécie em relação ao número total de plantas daninhas encontradas na área experimental;

${ }^{2}$ Os dados desta coluna indicam a \% da produção de matéria seca da espécie em relação ao peso total de plantas daninhas encontradas na área experimental

Tabela 2. Valores médios de peso de matéria seca $\left(\mathrm{MS}, \mathrm{g} / \mathrm{m}^{2}\right)$ acumulada pelas plantas daninhas, peso total de frutos (PTF, t/ha) e de frutos comerciais (PFC, t/ha) de tomate, sob a influência de diferentes períodos iniciais (dias) sem e com interferência (SI = no limpo e CI = no mato) das plantas daninhas durante o ciclo de desenvolvimento do tomate para processamento. Os dados de MS e PFC estão expressos em função das equações de regressão (Figuras 1 e 2). Brasília, Embrapa Hortaliças, 1997.

\begin{tabular}{lccccc}
\hline Tratamento & $\begin{array}{c}\text { Periodo } \\
\text { inicial } \\
\text { (dias, SI) }\end{array}$ & $\begin{array}{c}\text { Periodo } \\
\text { inicial } \\
\text { (dias, Cl) }\end{array}$ & MS $\left(\mathbf{g} / \mathbf{m}^{\mathbf{2}}\right.$ ) & PTF (t/ha) & PFC (t/ha) \\
\hline 1 & $1-28$ & - & 96,72 & 55,1 & 21,30 \\
2 & $1-35$ & - & 68,99 & 72,8 & 23,98 \\
3 & $1-49$ & - & 31,18 & 80,4 & 28,63 \\
4 & $1-63$ & - & 11,76 & 75,4 & 32,46 \\
5 & $1-77$ & - & 4,61 & 89,9 & 35,61 \\
6 & $1-91$ & - & 0,0 & 96,1 & 38,23 \\
7 & - & $1-28$ & 17,60 & 71,6 & 36,78 \\
8 & - & $1-35$ & 24,63 & 64,3 & 34,97 \\
9 & - & $1-49$ & 89,16 & 64,1 & 24,92 \\
10 & - & $1-63$ & 219,13 & 48,4 & 14,85 \\
11 & - & $1-77$ & 246,00 & 31,7 & 10,87 \\
12 & - & $1-91$ & 250,45 & 27,1 & 9,61 \\
\hline
\end{tabular}

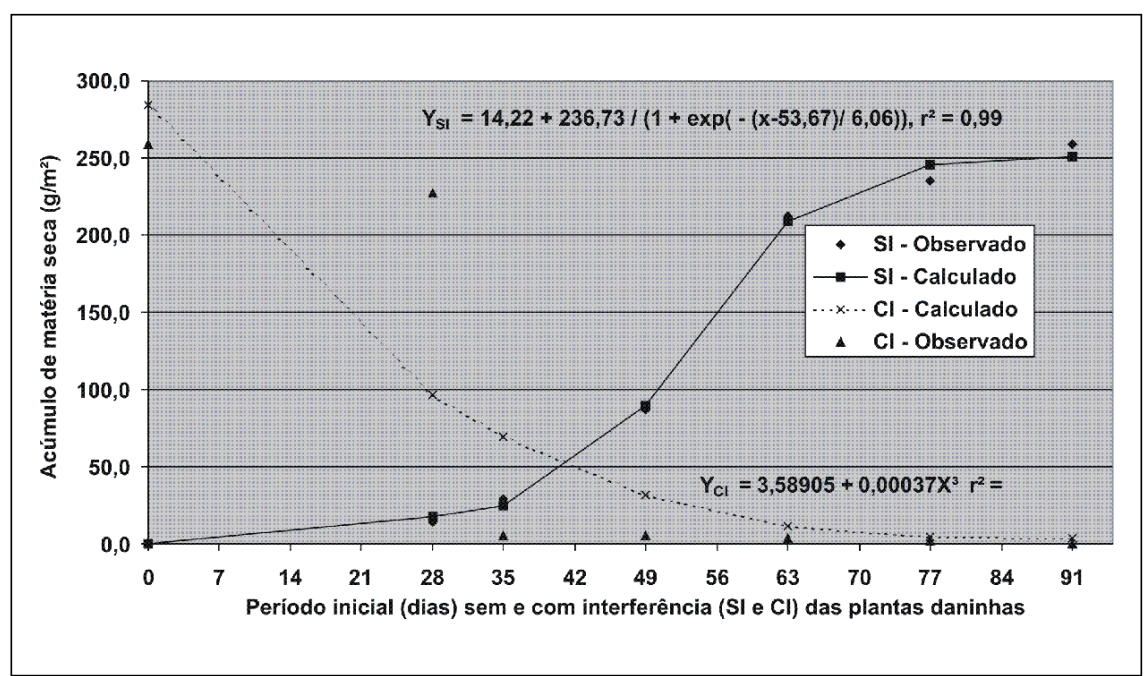

Figura 1. Acúmulo de matéria seca pelas plantas daninhas, em função dos períodos iniciais sem e com interferência $(\mathrm{SI}=$ no limpo, $\mathrm{CI}=$ no mato) na cultura de tomate para processamento, estabelecida por mudas transplantadas. Brasília-DF, 1997. equação de regressão, verificou-se tendência de acúmulo de matéria seca com o aumento da convivência com as plantas daninhas (Figura 1). Assim, com um período inicial de 28 dias com plantas daninhas obteve-se um valor de $17,6 \mathrm{~g} /$ $\mathrm{m}^{2}$, em contrapartida quando a convivência foi de 91 dias o valor estimado foi de $250,45 \mathrm{~g} / \mathrm{m}^{2}$. Corroborando com Qasem (1992) e Kuva et al. (2003), que descreveram que o peso de matéria seca das plantas daninhas aumentou com o aumento do período de interferência.

Os tratamentos com períodos iniciais sem interferência das plantas daninhas apresentaram menor acúmulo de matéria seca, quando comparado com os tratamentos que tinham períodos iniciais correspondentes com a interferência das plantas daninhas (Figura 1). Assim, verificou-se que o acúmulo de matéria seca das plantas daninhas que cresceram e desenvolveram até o $63^{\circ}$ dia foi de $219,13 \mathrm{~g} / \mathrm{m}^{2}$, ao passo que no tratamento correspondente, onde se permitiu que as plantas crescessem e desenvolvessem do $28^{\circ}$ dia até a colheita (total de 63 dias), o acúmulo de matéria seca foi de 96,72 $\mathrm{g} / \mathrm{m}^{2}$ (Figura 2 e Tabela 2). Essa menor agressividade das plantas daninhas que emergiram após o período inicial de 28 dias sem interferência (no limpo), é resultante da maior competição do tomateiro sobre as plantas daninhas e de um menor banco de sementes viáveis no solo após a ocorrência de um a dois fluxos de germinação das mesmas no referido período.

No tratamento em que as parcelas permaneceram inicialmente livres das plantas daninhas por 35 dias, e depois permitiu-se o crescimento e desenvol- 
vimento delas por 56 dias (até a colheita), o acúmulo de matéria seca pela comunidade infestante foi de $68,99 \mathrm{~g} / \mathrm{m}^{2}$, em contrapartida no tratamento em que as plantas daninhas cresceram durante o período do transplantio até 63 dias, o acúmulo de matéria seca foi de 219,13 $\mathrm{g} / \mathrm{m}^{2}$ (Tabela 2, Figura 1). Indicando novamente, a maior capacidade das plantas daninhas em acumularem matéria seca quando emergem no início do ciclo do tomateiro, exercendo certamente maior interferência sobre as plantas de tomate. $\mathrm{O}$ crescimento mais intenso das plantas daninhas ocorreu no período inicial com interferência de 49 a 63 dias, com acúmulo diário de 9,29 g de matéria seca $/ \mathrm{m}^{2}$.

Verificou-se também que o tratamento em que era permitida a convivência com plantas daninhas do $77^{\circ}$ dia após o transplantio do tomate até a colheita, apresentou acúmulo de matéria seca de apenas $4,61 \mathrm{~g} / \mathrm{m}^{2}$. Comparativamente ao tratamento todo ciclo com plantas daninhas, observa-se que o controle da plantas daninhas até a $11^{\mathrm{a}}$ semana promoveu uma redução de 61,66 vezes no peso da matéria seca das plantas daninhas (Figura 1).

Comparando-se o tratamento controle das plantas daninhas até o $28^{\circ}$ dia após o transplante do tomate com o tratamento controle de plantas daninhas até os 77 dias após o transplantio do tomate, verificou-se que houve redução no acúmulo de matéria seca de 96,72 para $4,61 \mathrm{~g} / \mathrm{m}^{2}$ (Tabela 2, Figura 1). Com isso a produtividade comercial subiu de 21,3 t/ha para 35,61 t/ha (Tabela 2, Figura 2). Observou-se, deste modo, que o aumento do período de controle inicial das plantas daninhas (de 28 para 77 dias) foi vantajoso, pois, reduziu o acúmulo de matéria seca das plantas daninhas e aumentou a produtividade do tomateiro em $67,2 \%$.

O tratamento sem plantas daninhas durante todo o ciclo da cultura, apresentou a maior produtividade comercial, 38,23 t/ha (Figura 2), valor próximo aos encontrados na cultura de tomate (Silva et al., 1994). Mesmo assim, houve grande perda de frutos, porque o período da colheita coincidiu com chuvas intensas, aproximadamente $80 \mathrm{~mm}$ por ocasião da colheita, que provocaram reduções drás-

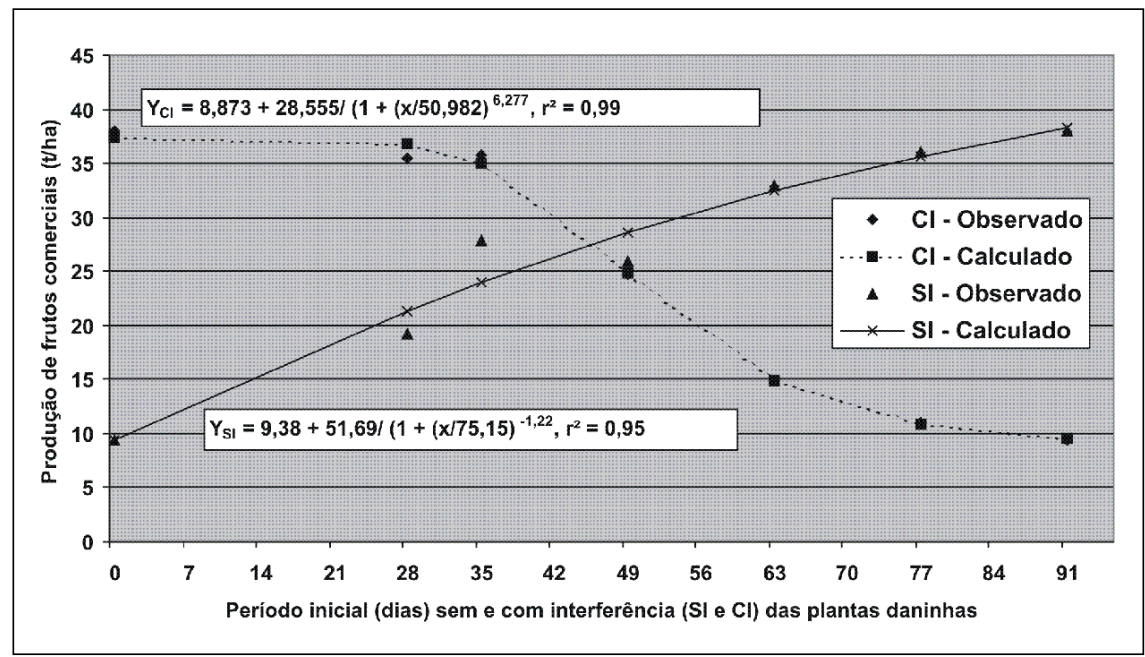

Figura 2. Influência das plantas daninhas na produção (t/ha) de frutos comerciais de tomate para processamento, em função dos diferentes períodos iniciais (dias) sem e com interferência (SI = no limpo, CI = no mato). Brasília-DF, 1997.

ticas na produção comercial, devido à incidência de patógenos e apodrecimentos de frutos (Tabela 2). Por outro lado, o tratamento com plantas daninhas durante todo ciclo apresentou a menor produtividade com 9,38 t/ha (Figura 2), $24,5 \%$ do potencial da produtividade comercial. Vários autores (Stall e Morales-Payan, 2003; Ngouajio et al., 2001; Norris et al., 2001, Qasem, 1992; Weaver e Tan, 1983; Friesen, 1979; Kasasian e Seeyave, 1969) relataram que a convivência com plantas daninhas causou redução na produtividade do tomateiro de $75 \%$ a $90 \%$.

Em função das equações de regressão (Figura 2) calculou-se o período de convivência, que foi 33 dias após o transplantio da cultura. Complementarmente, o período de controle também foi estimado, em função da equação de regressão, cujo valor foi de 76 dias após o transplantio das mudas. Assim, o período crítico de interferência das plantas daninhas para a cultura do tomate plantado por mudas foi de 33 a 76 dias (Figura 2). Neste período, o acúmulo de matéria seca pelas plantas daninhas foi de 223,4 g/m ${ }^{2}$ (Tabela 2), correspondendo a $89,2 \%$ em relação ao total de matéria seca acumulada pelas plantas daninhas durante todo o ciclo do tomateiro. $\mathrm{O}$ acúmulo médio diário da matéria seca das plantas daninhas, durante o PCI (33 a 76 dias) foi de 5,2 g, implicando uma redução na produção de tomate de 0,57 t/dia, no referido perío- do, ou seja, cada kg de matéria de seca acumulada pelas plantas daninhas provocou uma redução de 17,86 e 11,04 kg na produção total de frutos e de frutos comerciais de tomate, respectivamente (Tabela 2, Figura 2).

Estes resultados ressaltam a importância do controle das plantas daninhas pelo menos durante o PCI. A comunidade infestante que se instala após este período não tem mais condições de interferir significativamente na produtividade da cultura, entretanto, pode crescer e amadurecer, aumentando o banco de sementes no solo, bem como também servir de hospedeira de insetos-pragas e patógenos. Os valores encontrados para o PCI dependem das características de cada agroecossistema, como espécie, densidade e peso de plantas daninhas, condições climáticas, fertilidade do solo, entre outras. Campeglia (1991) encontrou para o tomate implantado através de semeadura direta PCI de 0 a 60 dias. Weaver (1984) e Weaver e Tan (1987), para o mesmo sistema, determinaram o PCI de 35 a 63 dias. No tomate para processamento transplantados o PCI foi de 24 a 36 dias, Friesen (1979); 28 a 42 dias, Sajjapongse et al. (1983); de 28 a 35 dias, Weaver e Tan (1983); 28 a 35 dias, Weaver (1984); de 28 a 35 dias, Qasem (1992); de 20 a 60 dias, Campeglia (1991) e de 26 a 46 dias, Hernandez (2004).

A maior amplitude no valor do PCI encontrado no experimento pode ser 
justificada pela forma de se realizar as análises estatísticas e as estimativas do PCI neste trabalho, os quais foram feitas através da equação de regressão, a maneira mais correta para se analisar os dados quando trata-se de níveis (dias com e sem plantas daninhas) (Gomes, 1977; Mosteller e Tukey, 1977; Little, 1978; Kleinbaum e Kupper, 1986).

\section{AGRADECIMENTOS}

Aos funcionários da Embrapa Hortaliças: Sr. Itamar da Silva Ribeiro e Sr. Cristiano da Silva, pela ajuda nos trabalhos. À AGENCIARURAL-GO, à Embrapa Hortaliças, pelas instalações e pessoal de apoio; e à CAPES pela concessão da bolsa de estudos.

\section{LITERATURA CITADA}

BLANCO, H.G. A importância dos estudos ecológicos nos programas de controle de plantas daninhas. O Biológico, São Paulo, v.38, n.10, p.343350, 1972.

CAMPEGLIA, O.G. Sanidad del cultivo: malezas. In: GALHARDO, G.; MONTE, R.F.; ARGERICH, C.; LIPINSKI, V.; CARRETERO, J.; CAMPEGLIA, O.G.; GATICA, M.; GRACIA, O.; VEGA, E.; RIQUELME, A.H., PUIATTI, A., MARTIN, G. El cultivo de tomate para industria. Cuyo: INTA, 1991. p.62-72. (INTA. Agro de Cuyo. Manuales, 1).

CANÇADO JÚNIOR, F.L.; CAMARGO FILHO, W.P.; ESTANISLAU, M.L.L.; PAIVA, B.M.; MAZZEI, A.R.; ALVES, H.S. Aspectos econômicos da produção e comercialização do tomate para mesa. Informe Agropecuário, Belo Horizonte, v.24, n.219, p.7-18, 2003.

FRIENSEN, G.H. Weed interference in transplanted tomatoes (Lycopersicon esculentum) Weed Science, v.27, n.1, p.11-13, 1979.
GOMES, P.G. Curso de Estatística Experimental. 7. ed. Piracicaba: ESALQ, 1977. 430 p. HERNANDEZ, D.D.; ALVES, P.L.C.A; SALGADO, T.P. Efeito da densidade e proporção de plantas de tomate industrial e de maria-pretinha em competição. Planta Daninha, v.20, n.2, p.229-236, 2002. HERNANDEZ, D.D. Efeitos da densidade e dos períodos de convivência de Solanum amaricanum no crescimento e produtividade do tomateiro para processamento industrial. 2004. 52p. (Tese mestrado), UNESP, Jaboticabal.

KASSIAN, L.; SEEYAVE, J. Critical periods for weed competion. Pans, v.15, n.2, p.208-12, 1969. KLEINBAUM, D.G.; KUPPER, L.L. Applyied regression analysis and other multivariable methods. Boston: Duxbury Press, 1986. 486 p.

KUVA, M.A.; PITELLI, R.A.; CHRISTOFFOLETI, P.I.; ALVES, P.L.C.A. Períodos de interferência das plantas daninhas na cultura da cana-de-açúcar. I - Tiririca. Planta Daninha, Viçosa, v.18, n.2, p.241-251. 2000.

KUVA, M.A.; GRAVENA, R.; PITELLI, R.A.; CHRISTOFFOLETI, P.I.; ALVES, P.L.C.A. Períodos de interferência das plantas daninhas na cultura da cana-de-açúcar. II - Capim-Braquiária (Brachiaria decumbens). Planta Daninha, Viçosa, v.19, n.3, p.323-330. 2001.

KUVA, M.A.; GRAVENA, R.; PITELLI, R.A.; CHRISTOFFOLETI, P.I.; ALVES, P.L.C.A. Períodos de interferência das plantas daninhas na cultura da cana-de-açúcar. III - Capim-Braquiária (Brachiaria decumbens) e Capim-Colonião (Panicum maximum). Planta Daninha, Viçosa, v.21, n.1, p.37-44. 2003.

LITTLE, T.M. If Galileo published in HortScience. HortScience, v.13, n.5, p.504-506, 1978.

MOSTELLER, F.; TUKEY, J.W. Data analysis and regression: a second course in statistics. Massachussetts: Addison-Wesley Publishing Company, 1977. 588 p.

NGOUAJIO M.; MCGIFFEN JUNIOR, M.E.; HEMBREE, K.J. Tolerance of tomato cultivars to velvetleaf interference. Weed Science, v.49, p.9198, 2001.

NORRIS, R.F.; ELMORE, C.L.; REJMÁNEK, M.; AKEY, W.C. Spatial arrangement, density, and competition between barnyardgrass and tomato: I - crop growth and yield. Weed Science, v. 49 , p.61-68, 2001.
PEREIRA, W. Manejo de plantas daninhas em hortaliças. Brasília: EMBRAPA-CNPH, 1987. 6 p. (Circular Técnica, 4).

PEREIRA, W. Manejo de plantas daninhas. In: SILVA, J.B.C.; GIORDANO, L.B. Org. Tomate para processamento industrial. Brasília: Embrapa Comunicação para Transferência de Tecnologia/ Embrapa Hortaliças, 2000. p.72-87.

QASEM, J.R. Pigweed (Amaranthus spp.) interference in transplanted tomato (Lycopersicon esculentum). Journal of Horticultural Science, v.67, n.3, p.421-427, 1992.

SAJJAPONGSE, A., SELLECK, G.W.; ROAN, Y.C. Weed control for transplanted tomato. Acta Horticulturae, v.136, p.65-72, 1983.

SILVA, J.B.C.; GIORDANO, L.B.; BOITEUX, L.S., LOPES, C.A.; FRANÇA, F.H.; SANTOS, J.R.M.; FURUMOTO, O.; FONTES, R.R.; MAROUELLI, W.A.; NASCIMENTO, W.M.; SILVA W.L.C.; PEREIRA, W. Cultivo do tomate (Lycoperiscon esculentum Mill.) para indutrialização. Brasília: EMBRAPA-CNPH, 1994. 36 p. (Instruções Técnicas, 12).

SILVA, J.B.C.; GIORDANO, L.B. Produção mundial e nacional. In: SILVA, J.B.C.; GIORDANO, L.B. Org. Tomate para processamento industrial. Brasília: Embrapa Comunicação para Transferência de Tecnologia/ Embrapa Hortaliças, 2000. p.8-11.

SILVA, A.C.; FERREIRA, L.R.; FERREIRA, F.A Manejo integrado de plantas daninhas. Informe Agropecuário, Belo Horizonte, v.24, n.219, p.9397, 2003.

STALL, W.M.; MORALES-PAYAN, P. The critical period of nutsedge interference in tomato. Disponível em <http://www.imok.ufl.edu/veghort/pubs/ workshop/Stall99.htm>. Acesso em 15 dez. 2003. WEAVER, S.E. Critical period of weed interference in three vegetable crops in relation to management practices. Weed Research, v.24, p.317-325, 1984.

WEAVER, S.E.; TAN, C.S. Critical period of weed interference in field-seeded tomatoes and its relation to water stress and shading. Canadian Journal of Plant Science, v.67, p.575-583, 1987. WEAVER, S.E.; TAN, C.S. Critical period of weed interference in transplanted tomatoes (Lycopersicon esculentum): growth analysis. Weed Science, v.31, p.476-481, 1983. 